\title{
Analysis of drainage canal defects and review of canal cleaner designs
}

\author{
Khamzat Abdulmazhidov* \\ Federal State Budgetary Educational Institution of Higher Education "Russian State Agrarian \\ University-Moscow Timiryazev Agricultural Academy", Timiryazevskaya street, 49, 127550 \\ Moscow, Russian Federation
}

\begin{abstract}
The drainage system elements, namely, the canals, lose their initial design characteristics over time. In general, the canals with unstable profiles are often in the reclamation construction. The problems of unstable profiles of the canals are, primarily, related to the physical and mechanical properties of soils, formation of internal mechanical, as well as chemical and biological processes occurring by the action of natural conditions. Maximum stability is characteristic for canals formed in cohesive organic soils, as well as in various kinds of peat with their thickness considerably exceeding the depth of the canal. With insignificant peat thickness above mineral soils, the stability of the drainage canal slopes will be rather insignificant. Wood peats are the most stable among organic soils. The canals laid in sapropelic soils characterized by the natural flow have rather low stability. That is why, the required stability in wet soils can be achieved by removing the excess moisture. The slopes of the canals made in various clays and loams with their large thickness considerably exceeding the depth of the canal have relatively high stability.
\end{abstract}

\section{Introduction}

Stability of the canals laid in the soils of different origin with various mechanical strength Ensuring the stability of the drainage canals and elimination of their deformations to a certain extent require the formation of slight slopes with shallow depth, however, such solution leads to widening the canal. And this is one of the deficiencies related to a reduction of the drained (reclaimed) area. The drainage canals of open streams made in various soil conditions and operated for a long period of time, with complex and various deformations, often become non-functioning. The most common kinds of canal deformations include: peat absorbing; slope destruction; underwater and slope erosion; bottom silting and accumulation of mud; canal silting and accumulation of mud; overgrowth of bottom, slopes and berms; destruction of benches, dump banks, conical depressions and mouths of canals; destruction of facilities.

Loss of function of the drainage canals can occur under the influence of natural and artificial operation conditions. The negative natural operation conditions include: overgrowth of bottom and slopes of drain ditches with grassland vegetation and small shrubs, and small

* Corresponding author: hamzat72@mail.ru 
trees in some cases; slope destruction due to periodical freezing and melting of top soil; sedimentation in the flood period; landslide developments and soil settlement; significant silting of closed drainage connected to the canal, etc. [1,2].

The artificial operation conditions that have negative influence on the drainage canal operation include: non-compliance with technical requirements during the engineering and construction of hydro-reclamation systems; steep slopes; disturbed canal bottom slope. Significant adverse impact on drainage canals is made by non-compliance with technical documentation of the system by business companies in general; crossing over the canals by tractors and other agricultural machinery; clogging of the canal with stones, weeds and garbage (Fig. 1).
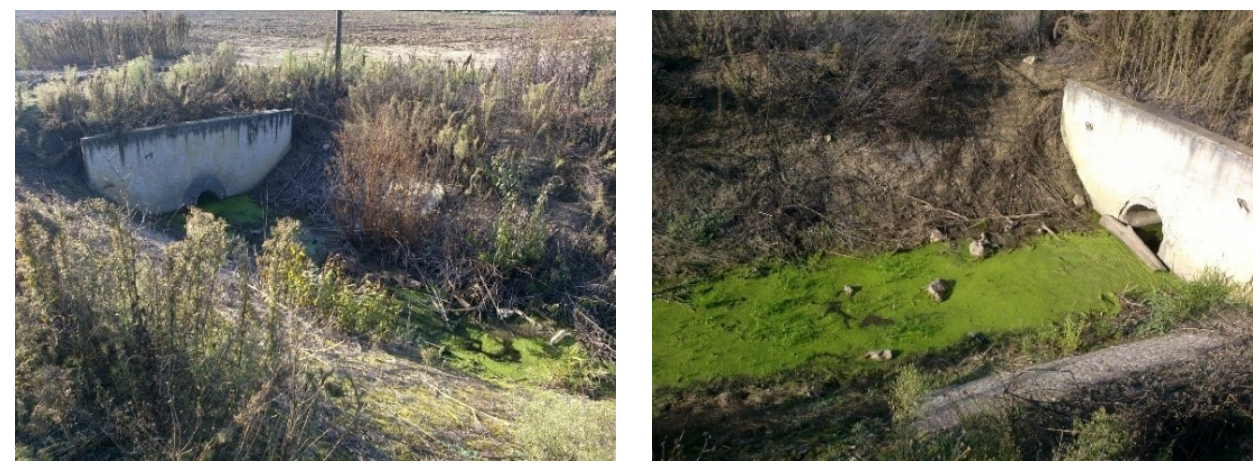

Fig. 1. Condition of the drainage canal and its facilities in long-term operation without current and capital repairs

The initial structural cross-section of the canal disappears, namely, it becomes smaller as a result of an accumulation of vegetation on the canal slopes and bottom, in addition, the bed roughness significantly increases, all these reduce the cross-section throughput and facilitate intense silting. Vegetation in the canal leads to increase in the roughness coefficient from allowable values of 0.003 to high values of about 1.7 and more. The all round overgrowth of the canal bed with hydrophilious vegetation is usually observed in the areas with low water flow rate $[3,4]$.

The most common kind of canal deformation is soil creep in case of melting and degradation of slopes by surface waters. The soil creep and degradation of slopes are also caused by the presence of the mineral layer or the water-saturated soil layer under the upper coherent soil layer in the slope base. As a result of creeping, the slope becomes more flat, correspondingly, the canal width increases.

Such phenomena as slope erosion and silting even in the small areas can impair the operation of the whole drainage system. These processes usually occur during the spring flood period. In the other periods, the canal erosion and silting may occur but not so catastrophic. This is also due to the canal crossing the loose soils, canal turns of large radius of rounding and drastic slope change.

The intense silting of the canal bottom is usually observed in the areas where the water flow rate drastically decreases. The deposited silt particles rise the water level and impair the system operation.

Draining the peaty and mineral soils leads also to their absorbing. When the peat layer is drained, soil absorbing can reach $40 \%$, and in clay soils, it can be within $10 \%$ of the bed depth nearby the channel. The negative impact of soil absorbing consists in decrease in the transverse and longitudinal profiles of the canal. To avoid soil absorbing, the soil excavated from the canal should be placed in a significant distance from the canal bench during canal construction. Moreover, it is necessary to provide the bench width for various service equipment passing. 
The drain ditches are the part of shallow network which depth varies within 0.8 and 1.7 $\mathrm{m}$. This parameter makes primarily about $1.2 \mathrm{~m}$.

Restoration and repair of drainage canals require the selection of certain types of machines which controls are designed for operation with the drain ditches having specific geometry. Such parameter of the canal as the width along the bottom is important during development of the operating equipment of the canal cleaners. For most of the drainage canals, this parameter is within 0.2 and $0.6 \mathrm{~m}$. The width along the bottom of $0.2 \mathrm{~m}$ is characteristic for canals made by plow-type ditchers. In the territory of the Russian Federation, such equipment has not been virtually used in making the long-length canals.

The percentage of the canal width along the bottom for various zones is given in Table 1.

Table 1. Width along the bottom of open ditchers

\begin{tabular}{|c|c|c|}
\hline Width along the bottom & $\begin{array}{c}\text { Russian Federation } \\
\text { (Smolensk region) }\end{array}$ & Belarus \\
\hline $0.2 \ldots 0.25$ & none & $26.0 \%$ \\
0.4 & $87.0 \%$ & $49.0 \%$ \\
0.6 & $10.0 \%$ & $19.0 \%$ \\
over 0.6 & $3.0 \%$ & $6.0 \%$ \\
\hline
\end{tabular}

From the point of view of ensuring the stability of drainage canal slopes and their mechanical cleaning, such parameter as the ratio of slope is important. For most elements of the drainage network, the ratio of slope is within $1: 1$ and 1:1.5. The canals with slighter slopes make $1 \ldots 4 \%$. This is explained by that the steeper slopes are less stable, and the performance of the canals with slight slopes is low. With the average deep of the canal being equal to 1.5 $\mathrm{m}$, the width along the top will be within $5 \ldots 6 \mathrm{~m}$. The low values of the canal width along the top make it possible to use the cleaning machine operating according to the saddle scheme.

For quality functioning of drainage systems, it is necessary to take into account that it is much easier to prevent a canal deformation than to correct it, that's why the regular maintenance and control over the condition of all elements of the drainage network are required. The most common canal deformation, the overgrowth of the bottom and slopes with vegetation, is a significant deformation caused by natural factors. The process of overgrowth of the slopes develops so quickly that the effect from the performed cleaning works is brought to a minimum. Grassland vegetation on the slopes should be cut down. It is desirable to perform this process before blossoming at the end of May - in the beginning of June taking into account that there is few water in the canals during this period. All the cut vegetation should be taken out of the canal.

The low water flow rate in the canal facilitates the growth of vegetation, and the high flow rate exceeding the critical value can lead to erosion. In the soils with low erosion resistance, it makes sense to maintain the bottom inclination. It is known that the scouring action of the water flow will be stronger if to reduce the section, in view of this, to avoid erosion, all obstructions compressing the water flow should be removed from the canal. To avoid erosion, the areas with weak slopes and bottom should be strengthened by gravel, fagot structures, rock blankets or plank structures. The wet slopes should be strengthened by stone and porous concrete slabs, and the dry slopes can be grassed.

The measures to fight against sedimentation are brought to the activities against bed erosion, catchment of rain and melt waters at water discharge or construction of additional catch drains and creation of uniform non-silting flow rates. Also in places where sedimentation is possible, for example, in the areas of descending inclination of the canal bottom, the setting reservoirs are arranged. 


\section{Materials and Methods}

The materials and methods for eliminating the defects of the drainage canals and the ways to implement them offered in this article are mainly related to the review of design of different kinds of canal cleaners and to the selection of the optimal complex on the basis of their performance indicators. During the 1960s and 1970s, special canal cleaners started being developed. To create special-purpose equipment for canal cleaning, the common construction bucket excavators with various kinds of detachable operating equipment were used. The operating equipment of the bucket excavator, a dragline with side attachment, was mainly used. Such design made it possible to clean the canal bottom with the bucket moving longitudinally along the canal axis. But the dragline could not qualitatively clean the sediments off the canal bottom in the framework of regular repairs. There appeared new canal cleaners with new kinds of the operating equipment that differed by the operation mode (cyclic and continuous), method of attachment (with side attachment, with rear attachment), type of base machine (crawler or pneumatic-tyre tractor), arrangement of base chassis and operating unit (cantilever-type, saddle-type, in-the-canal operation scheme), operating unit design (single bucket, multibucket, cutting-type, scraper, rotary) [5].

The scopes of cleaning works on the reclamation drainage systems is though less than when laying new canals but not remain rather extensive. This requires the creation and use of high-performance machines. The operation of canal cleaners should not create difficulties in transportation, as well as in relocation from one object to the other. In addition to the other properties, the specialized canal cleaner should have high-quality performance. In terms of performance indicators, the continuous-type machines have advantages before the intermittent-type canal cleaners. However, it cannot be always stated in such unambiguous way. The operating equipment aggregated with general-purpose tractors will also have a certain advantage, such decision makes it possible to reduce the cost of use of canal cleaners. If the business company has various kinds of base machine (crawler or pneumatic-tyre tractor), the use of specialized replaceable working equipment obviously reduces the cost of cleaning operations in contrast to the necessary manufacture of base machine $[6,7]$.

The canal cleaners with cantilever-type attachment of the operating equipment are most widely used, their advantages are quite significant. Such scheme provides for multi-purpose use of machines, allows for bypassing various obstacles located in the canal bed (this is rather difficult operation for saddle-type scheme), performing cleaning operations in any kinds of deformations. The disadvantage of such scheme are the difficulties in ensuring stability of the base machine.

The saddle-type scheme has its advantages and disadvantages: firstly: the stability is ensured irrespective of arrangement of the operating equipment elements as the center of gravity will be always within the support contour; secondly, the machine can transfer along the benches. However, the canal cleaners operating according to the saddle-type scheme are cumbersome with due regard to that the gauge of tracks of wheels should be more than the canal width along the top.

In the cases when driving along the benches is impossible due to tree planting, pasture fencing and other facilities on the canals, the canal cleaners operating within the canal contour with wheel or floating travel device may compete with the basic kinds of machines. The in-the-canal cleaners have not been widely used as they can move only over rather flat slopes and along the wide bottom, as well as with the high soil bearing capacity under the carrying wheels, and this is a rare case for the drainage systems.

Therefore, the cantilever-type scheme of attachment of operating units is the most advantageous that is agreeable to experience.

The multibucket canal cleaners have mainly the traversal digging scheme. The quality and performance characteristics of this kind of continuous-type machines are rather high even 
at low power costs. These machines are especially efficient for capital repairs when it is required to restore the initial geometrical profile. The positive characteristics of the multibucket canal cleaners can include: separate cleaning both of the bottom and the slopes; operability even in the conditions of wood and stone inclusions; adaptability to work with the wet soil not sticking to the operating equipment elements, as the operating equipment includes the forced cleaning mechanisms; operability in the watered canals; possible cleaning when moving both forwards and backwards. One of the disadvantages of such machines is shouldering the lower parts of the slopes that leads to the impaired geometrical parameters of the canal cross-section.

The multibucket canal cleaners have become most widely used in Belarus where the opencut drain is a common practice, in the Russian Federation, the use of such machines is limited due to a small number of shallow drainage network and its short length. Of course, there were the attempts to create multibucket canal cleaners for operation in the canals with the depth of to $3 \mathrm{~m}$. However, such structures were rather cumbersome and were not widely implemented.

The creation of canal cleaners with the scraper-type operating unit was limited by manufacture of pilot samples which testing identified the deficiencies that consisted in the limited use (only on peat soils), quick wear of the chain-drive operating unit and soil pelting of the base machine.

The cutting-type canal cleaners have relatively wide range of products and are mounted on the base crawler tractors of drawbar categories 3.0..6.0. Such machines are used for regular repairs when only the bottom deposits are to be cleaned off. The feature of the cuttingtype canal cleaners is high rotation of the cutter that cuts the soil layer 10-30 cm thick and spreads it in the distances of 10-15 m from the edge of the canal without dike formation. The most efficient cutting-type canal cleaners work on the wetlands with the water level of 15-20 $\mathrm{cm}$ in the canals. Such conditions occur during cleaning operations of the drainage system. However, with higher water levels, the cutting-type canal cleaner performance decreases. Also, it is rather difficult to operate the cutting-type canal cleaners in the mineral dry soils with rocky inclusions, such operation leads to heavy and quick wear of blades with cutting elements of the cutter. The main disadvantage of the cutting-type canal cleaners consists in poor quality of works and impossibility to reach the initial design dimensions of the canal. Hence, it follows that the cutting-type canal cleaners must not be used as the base machines of complexes for regular repairs of canals.

The next kind of machines used for canal cleaning, the bucket-type canal cleaners, are rather common and still manufactured at the plants of the Russian Federation and Belarus. Irrespective of that they are cyclic-type machines and their performance fall short of that of the intermittent-type machines, and are efficiently used by the land-reclamation companies. When there are no special-purpose machines, standard construction bucket excavators are often used. Some land-reclamation companies use the replaceable extended buckets for bucket excavators. The main advantages of such machines include simple design and multipurposeness that provide for performing cleaning operations in various conditions. As of today, it can be stated that the bucket canal cleaners together with the bucket excavators still take the leading position in the use of complexes of machines during repair operations on the reclamation systems. Their efficient use is related to specific volume of the sediments. Statement that the bucket excavators are efficient on the drainage systems does not refer the non-full swing bucket excavators with rear attachment of the operating equipment to the standards pneumatic-tyre tractors (for examples, analogues of EO-2621 excavator). Such machines can be used for small work scopes and in particular cases when the frequent pointto-point operation is not required.

The bucket excavators with replaceable extended reclamation buckets for traversal digging are the most efficient from the group of machines being considered. The following characteristics of the excavators are the most critical during cleaning operations: insignificant 
operating weight to avoid additional deformation of the canal bed; full-circle operating equipment to ensure full operating cycle with soil unloading in the sufficient distance from the edge of the canal; crawler attachment to ensure minimum specific pressure on the soil and stable operation during soil and sediments digging, moreover, the point-to-point motion trajectory of the machine is always parallel to the canal axis.

The low performance of the bucket cleaners and excavators is not their main disadvantage. The work quality is more important, i.e. significant overdigs during repair, required additional planning, installation of fixtures in particular cases, all these considerably increased the cost of the cleaning operations performed. But all the same, simple design, reliability and multipurposeness are the prerequisites for development of the bucket cleaners.

The main area in development of the bucket canal cleaners is to make the bucket move along the longitudinal axis of the canal in contrast to the traversal digging machines. The dragline with side attachment was such first machine, but it has not been widely used due to its cumbersome design.

Berkenheger firm offered interesting design decisions that consisted in mounting of the operating equipment, the backhoe, on the powered chassis capable of functioning both according to the saddle-type and in-the-canal scheme. These schemes were further developed, in addition to that the full-circle wheel machine resting upon the slope could move along the canal axis, the sediments could be removed both using the backhoe along the canal axis. Such system is quite operable on the shallow network systems, but there appear difficulties in the bucket unloading in significant distances from the edge of the canal when cleaning the deep canals.

Often, it is necessary to preserve the slope strengthening structures, as well as to ensure the turf integrity on the canal slopes during cleaning operations. Such requirements can be complied with only when the canal cleaners with the bucket moving longitudinally along the canal axis are used. The most efficient and promising in this case can be the crawler-tractor based machine, drawbar category 3 , with the bucket moving longitudinally along the canal axis on rigid guides. The longitudinal motion of the bucket is provided by the used rigid transverse beam made of beam channels along which the bucket moves by the action of hydraulic cylinders and four-fold high-speed block pulley $[8,9]$.

\section{Results and Discussion}

Irrespective of the relatively low performance, the canal cleaner with the bucket on rigid guides ensures high quality of the performed cleaning operations, this is confirmed by the field tests conducted. The strictly straight line motion of the bucket with the regulation of chip thickness and the use of replaceable buckets of various width corresponding to the width along the bottom of the most of drainage canals, as well as with the function of soil and sediments development from under water make the machine demanded and necessary for cleaning and recovery in the framework of regular and capital repairs. The canal cleaner is capable of working on the canals clogged with wood and stone inclusions. The use of this crawler-tractor based machine with the use of extended tracks makes it possible to ensure stable operation of the machine in various conditions.

Considering that the bearing capacity of the slopes can appear to be considerably lower than that of the benches, the strict flotation requirements are established for attachments of in-the-canal machines. In the operating equipment of the canal cleaner, it is recommended to use the trapezoidal cross-section bucket (Fig. 2) duplicating the lower levels of the canal that will clean not only the bottom from sediments and siltage but also bottom-related parts of the slopes to prevent the cut part from creeping. 


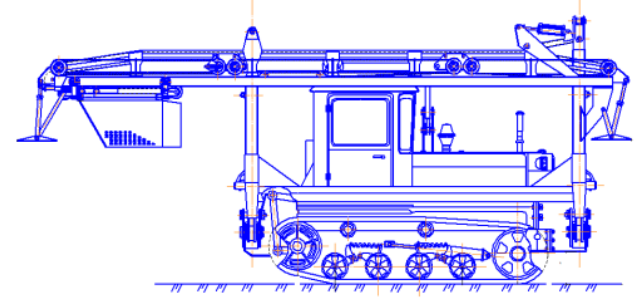

$a$

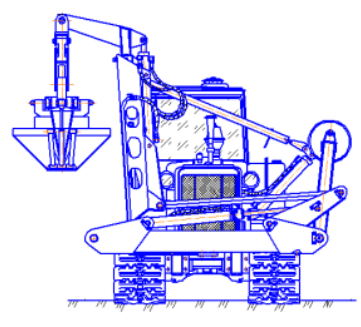

$b$

Fig. 2. Canal cleaner with the bucket on rigid guides: $a$-side view, with the trapezoidal cross-section bucket - front view

Such advantages allow to consider the canal cleaner with the bucket on rigid guides as a leading machine of particular complex.

It is obvious that the highest effect will be achieved with the comprehensive use of canal cleaners with passive and active operating units.

\section{Conclusions}

1. The conducted analysis of defects of drainage canals shows that their current condition is ambiguous. The canals require repairs with the use of various kinds of machines.

2. The review of the canal cleaners allows for stating that there are various kinds of machines with the operating units suitable for the corresponding operation conditions.

3. The multibucket canal cleaners have the best performance.

4. The canal cleaners with the bucket-type operating units are the most universal.

5. By the quality of the conducted cleaning operations, the canal cleaners with the bucket moving longitudinally along the canal axis are the most promising. Moreover, the efficiency of such machines increases with the use the buckets of different width and profile according to the parameters of the cleaned canal.

\section{References}

1. N.N. Dubenok, Yu.G. Yanko, A.F. Petrushin, R.V. Kalinichenko, Modern Problems of Remote Sensing of the Earth from Space, 16(3), 96 (2019)

2. F. Abdrazakov, A. Rukavishnikov, O. Miheeva, C. Churkina, M. Yarmashevich, IOP Conference Series: Materials Science and Engineering, 883(1), 012209 (2020)

3. F.K. Abdrazakov, A.A. Rukavishnikov, A.V. Povarov, Y.E. Trushin, E3S Web of Conferences, 140, 09009 (2019)

4. N. Martinova, K. Shavazov, N. Telovov, S. Toigambayev, S. Yusupov, IOP Conference Series: Earth and Environmental Science, 614(1), 012145 (2020)

5. Y.N. Nikolskii, I.P. Aidarov, C. Landeros-Sanchez, V.V. Pchyolkin, Irrigation and drainage, 68 (5) (2019)

6. S.-H. Cheng, L. Wang, Y.-B. Wang, Z.-Z. Wang, B.A. Engel, Irrigation and drainage, 68 (5) (2019)

7. A. Singh, Irrigation and drainage (2020)

8. H. Ojaghlou, T. Sohrabi, H. Javani, F. Abbasi, Irrigation and drainage (2020)

9. A.L. Buber, I.G. Bondarik, A.A. Buber, Irrigation and drainage, 69 (1) (2020) 